\title{
Characterization Studies on Adsorption of Lead and Cadmium Using Activated Carbon Prepared from Waste Tyres
}

\author{
H. Joga Rao $\dagger$ \\ Department of Chemical Engineering, GMR Institute of Technology, Rajam-532127, Andhra Pradesh, India \\ †Corresponding author: H. Joga Rao; hjrgmrit@gmail.com
}

Nat. Env. \& Poll. Tech.

Website: www.neptjournal.com

Received: 08-04-2020

Revised: 30-05-2020

Accepted: 04-06-2020

Key Words:

Activated carbon

FTIR

SEM

XRD

Crystalline index

\begin{abstract}
The aim of this work was to investigate the utilization of waste tire carbons as a low cost adsorbent for the removal of cadmium and lead ions from an aqueous solution. Surface functional groups would help in getting thorough knowledge about the adsorption capacity of the adsorbent. Thus, activated carbons were prepared from waste rubber tyres and characterized by means of field emission scanning electron microscopy, energy-dispersive X-ray and Fourier transform infrared spectroscopies. The FTIR spectra show that the adsorption peaks are shifted or disappeared and new peaks are formed which was due to the adsorption of lead and cadmium onto the adsorbent surface. It is evident that the characteristic adsorption peak of O-H stretching vibration was shifted from 3900 and $3075 \mathrm{~cm}^{-1}$ for lead and the asymmetrical stretching vibration at $3900 \mathrm{~cm}^{-1}$ was shifted to $3675 \mathrm{~cm}^{-1}$ for cadmium. This shift in peak indicates the interaction between metal ions and $-\mathrm{OH}$ groups of adsorbent due to the presence of alcohols, phenols, and carboxylic acid and which shows the decrease of free hydroxyl group content due to the interaction between lead cadmium with -OH groups of the adsorbent. SEM micrograph of adsorbent before adsorption is highly heterogeneous and the surface morphology of the adsorbent is rough. The pores were completely filled with the metal ions after the adsorption of lead and cadmium metals and the pores appear to be smooth. This observation indicates that the metal is adsorbed to the functional groups present inside the pores. From the XRD analysis, the $\mathrm{Cl}$ index for raw, lead and cadmium loaded activated carbon of waste tyres were found to be $48.91 \%, 81 \%$, and $54.9 \%$ respectively. These values clearly showed the increase in crystalline material present in the adsorbent after the adsorption of metal ions, which was due to the adsorption of metal ions onto the surface of the adsorbent.
\end{abstract}

\section{INTRODUCTION}

Prosperity may serve victory, but at the same time may also serve misfortune. Brisk Industrialization in the early ' 70 s in India has led to prosperity as per economy and in turn, has also led to hindrance in waste disposal. Deterioration in the environment has created havoc in India. The Industrial Revolution marks a major turning point in history; almost every aspect of daily life was influenced in some way. In particular, average income and population began to exhibit unprecedented sustained growth. The future seemed to be a catastrophe resulting in many unknown diseases created by this Industrial revolution (Akunwa et al. 2014, Nagajyoti et al. 2010). Researchers then focus on this to prevent water pollution and air pollution for improving the quality of water and air. There are several chemical methods for the pre-treatment which may also leave toxic chemicals at the end (Fu et al. 2011, Debasree et al. 2014). The chemical pollutant not only causes safety hazards and medical threats but also disturbs the stability of the environment (Bohli et al. 2013,
Amuda et al. 2007). Due to their hazardous effects, persistency and accumulation tendency, heavy metals can pose a risk to human and environmental health (Ku \& Peters 1987, Krishnan \& Anirudhan 2002). Due to rapid industrialization, toxic metal pollution is increasing causing destabilization in the ecosystem. The trace metals present are divided as heavy metals and light metals based on their densities (Foo \& Hameed 2010, Kobya et al. 2005). Toxic heavy metals include chromium, cadmium, mercury, silver, lead and tin, although several nutrient metals, notably zinc, copper and nickel, can also be toxic at elevated concentrations (Momcilovic et al. 2011). If not properly managed, industrial wastewater is responsible for severe damage to the environment and adversely affecting the health of the people. Some of the heavy metal effluents discharged by different industries are shown in Table 1 (Venkatesan \& Senthilnathan 2013, Chowdhury et al. 2012). It is of prime importance to prevent the accumulation of heavy metals all above their threshold concentrations. Heavy metals that affect the human organs are shown in Table 2 (Mona et al. 2014, Umar et al. 2015). 
Table 1: Heavy metals present in effluents discharged by different industries.

\begin{tabular}{|ll|}
\hline \multicolumn{1}{|c|}{ Industry } & Heavy metals present in the effluent \\
\hline Chloro-alkali & $\mathrm{Cr}, \mathrm{Cd}, \mathrm{Cu}, \mathrm{Pb}, \mathrm{Zn}, \mathrm{Hg}, \mathrm{Se}$ \\
Paints and dyes & $\mathrm{Cr}, \mathrm{Cd}, \mathrm{Cu}, \mathrm{Pb}, \mathrm{Zn}, \mathrm{Se}$ \\
Petroleum refinery & $\mathrm{Cr}, \mathrm{Cd}, \mathrm{Cu}, \mathrm{Pb}, \mathrm{Zn}$ \\
Fertilizers & $\mathrm{Cr}, \mathrm{Cd}, \mathrm{Cu}, \mathrm{Pb}, \mathrm{Zn}, \mathrm{Hg}, \mathrm{Mn}, \mathrm{As}$ \\
Motor vehicles & $\mathrm{Cr}, \mathrm{Cd}, \mathrm{Pb}, \mathrm{Zn}, \mathrm{Hg}, \mathrm{Se}$ \\
Mining and metallurgy & $\mathrm{Cr}, \mathrm{Cd}, \mathrm{Cu}, \mathrm{Zn}, \mathrm{Hg}, \mathrm{Se}, \mathrm{As}$ \\
\hline
\end{tabular}

Table 2: Effect of pollutants on human organs.

\begin{tabular}{|ll|}
\hline $\begin{array}{l}\text { Heavy metal } \\
\text { pollutants }\end{array}$ & Target organ \\
\hline Chromium & Stomach, lower respiratory system, skin and lungs \\
Cobalt & Liver, kidneys and bones \\
Cadmium & Blood, kidneys, bones and teeth \\
Nickel & Intestines \\
Lead & Blood, brain, bones, kidneys and teeth \\
Mercury & Blood and kidneys \\
Arsenic & Blood and kidneys \\
\hline
\end{tabular}

Among all the heavy metals, $\mathrm{Pb}$ (II) and Cd (II) are the predominant ones as they are generated from a majority of industrial operations such as metal plating industries, electroplating industries, steel making and alloy industries, petrochemical industries, refining of ores, and battery production (Fu \& Wang 2011). In the current years, the need for safe and economical methods for the elimination of heavy metals from contaminated waters has necessitated research interest towards the production of low cost alternatives (Gupta et al. 2011a). The search for new technologies involving the removal of toxic metals from wastewaters has directed attention to adsorption, based on the binding capacities of various materials. In recent years, research interest in the production of low cost activated carbon produced from unused materials has grown. Low cost activated carbons prepared from waste materials containing acidic groups such as hydroxyls and carboxyls were effective in binding metal cations (Girods et al. 2011, Gupta et al. 2011b). With this brief introduction about heavy metal pollution and importance of the lead and cadmium removal in particular from wastewater streams, an attempt has been made to study the use of low cost activated carbon from waste tyres as an adsorbent to treat the simulated metal solutions. In that context, The first aspect is related to the characteristics of the adsorbent such as surface area, porosity and the number of functional groups (Abdulaziz et al. 2013, Umar et al. 2015). The second factor is related to the characteristics of metals that are being sorbed; these include metal speciation in solution. The objective of the present study is to investigate the feasibility of an alternative, low cost and novel adsorbent for efficient removal of cadmium and lead from an aqueous solution. The functional groups on the surface of the adsorbents that contribute to the adsorption are characterized using Fourier transform infrared spectroscopy (FTIR), Scanning Electron Microscope (SEM) and X-Ray Diffraction (XRD) analyses.

\section{MATERIALS AND METHODS}

\section{Chemicals and Reagents}

The chemicals of AR/LR grades supplied by different standard manufacturing industries are shown in Table 3.

\section{Instrumentation}

Orbital shaker, $\mathrm{pH}$ Meter with a glass electrode, Filter, Analytical Balance, Atomic Absorption Spectrometer (AAS) (Perkin Elmer model 400A), FTIR, SEM and XRD.

\section{Preparation of Adsorbents}

The adsorbents prepared from waste tyres used in the present study were collected in Rajam and Srikakulam, Andhra Pradesh, INDIA. The adsorbents were prepared by carbonization and activation of carbonaceous materials by chemical activation methods (Juan et al. 2013, Nadeem et al. 2006). The dried products of adsorbents were sieved to the desired

Table 3: Chemicals and reagents.

\begin{tabular}{|llll|}
\hline Reagent & Company & Purity & Grade \\
\hline $\mathrm{Pb}\left(\mathrm{NO}_{3}\right)_{2}$ & Loba Chemie Pvt. Ltd. Mumbai & $99 \%$ & AR \\
$\mathrm{Cd}\left(\mathrm{NO}_{3}\right)_{2}$ & S. D. Fine Chem. Pvt. Ltd. & $99.5 \%$ & AR \\
$\mathrm{NaOH}$ & Loba Chemie Pvt. Ltd. Mumbai & $98 \%$ & AR \\
$\mathrm{HCl}$ & Sarabai Company, India & $35 \%$ & AR \\
$\mathrm{ZnCl}_{2}$ & Fischer Inorganics Ltd. & $70 \%$ & LR \\
$\mathrm{H}_{2} \mathrm{O}_{2}$ & S. D. Fine Chem. Pvt. Ltd. & $30 \%$ & AR \\
\hline
\end{tabular}

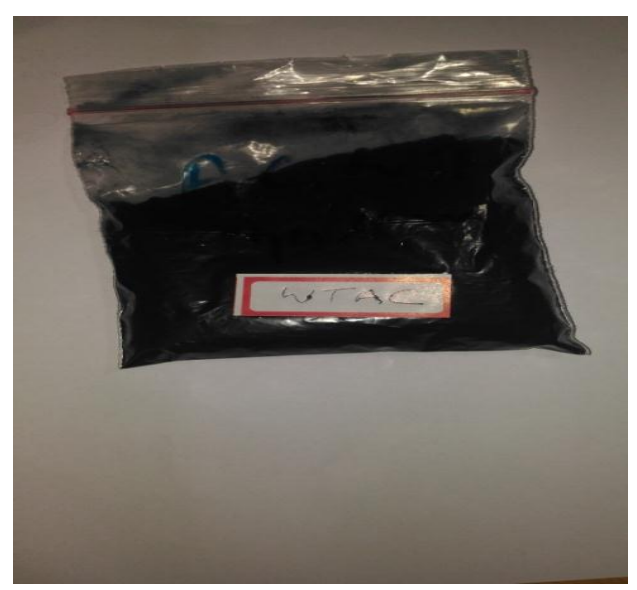

Fig. 1: Activated carbons prepared from waste tires with an average particle size of $149 \mu \mathrm{m}$. 
particle size range of 74-177 $\mu \mathrm{m}$ (Fig. 1). SEM micrographs showed the binding of metal ions on the surface of the adsorbents. FTIR analysis indicated the presence of various functional groups such as hydroxyl, carboxyl, amino, etc., on the surface of the adsorbent which was responsible for the adsorption of metals. XRD studies confirmed the crystalline and amorphous nature of the adsorbents.

\section{RESULTS AND DISCUSSION}

\section{SEM analysis of Activated Carbon of Waste tyres Adsorbent}

SEM is an electron microscope, which provides images of the sample surface by scanning it with a high-energy beam of electrons. The electron interactions with the atoms of the sample produce signals that contain information about the topography, morphology, and composition of the sample surface. The SEM analysis of activated carbon of waste tyres was carried out to study the porosity and surface structure of adsorbent. Fig. 2 shows the SEM micrograph of activated

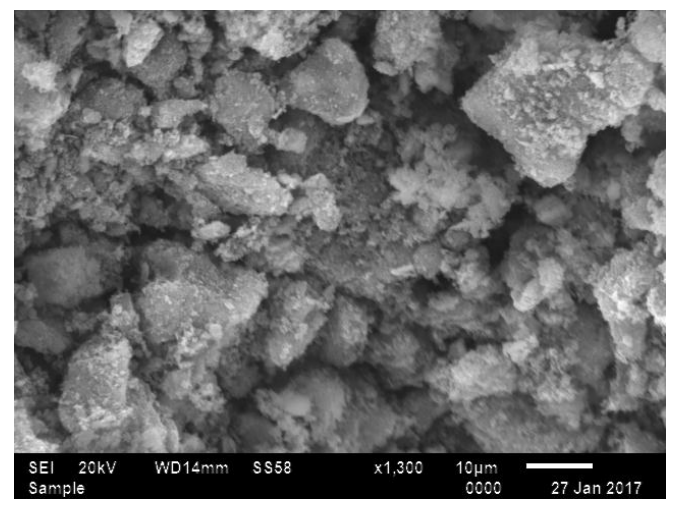

Fig. 2: SEM micrographs of activated carbon of waste tires adsorbent before adsorption.

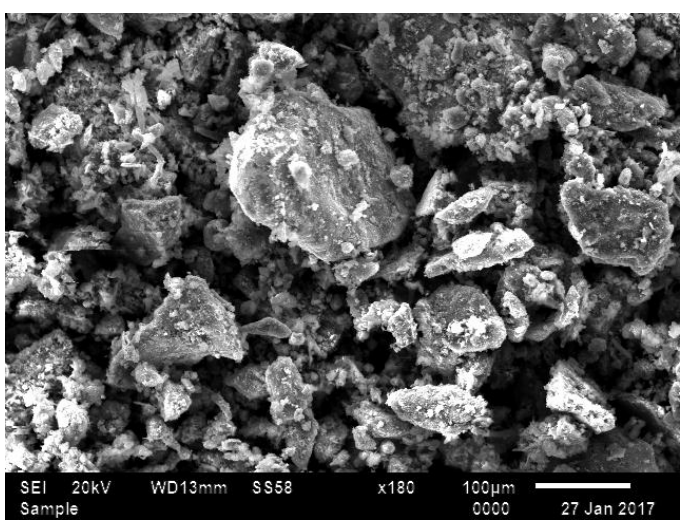

Fig. 3: SEM micrographs of activated carbon of waste tires adsorbent after adsorption with lead.

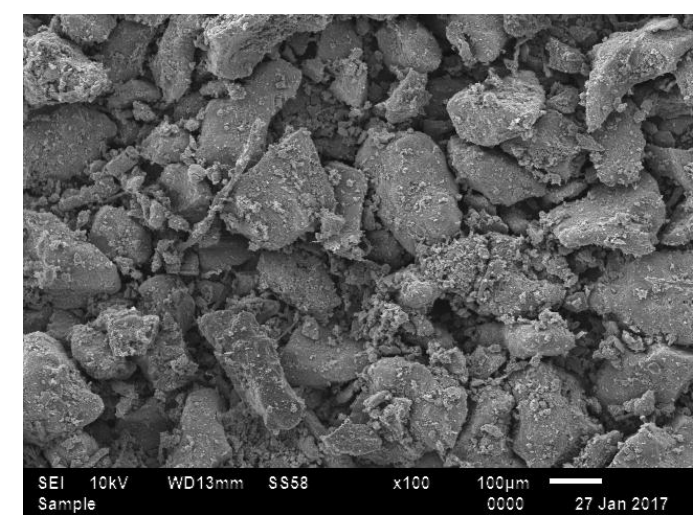

Fig. 4: SEM micrographs of activated carbon of waste tires adsorbent after adsorption with cadmium.

carbon of waste tyres before adsorption. It is evident from the figure that the adsorbent is highly heterogeneous and the surface morphology of the adsorbent is rough. It is clear that the adsorbent has a considerable number of heterogeneous layer pores where there is a good possibility of heavy metal being adsorbed. Figs. 3 and 4 show the SEM micrographs of activated carbon of waste tyres after adsorption of lead and cadmium respectively. It is evident from these figures that the surface texture of activated carbon of waste tyres was completely changed before and after the adsorption of heavy metals. The surface of the metal-loaded adsorbent clearly shows that the surface of the adsorbent dosage was covered with metal ions. The pores were completely filled with the metal ions after the adsorption of lead and cadmium metals and the pores appear to be smooth. This observation indicates that the metal is adsorbed to the functional groups present inside the pores. The surface of the adsorbent became smooth after the adsorption of lead and cadmium metals. Smoothening of the surface is due to the adsorption of metal ions onto the pores of the adsorbent. It may also occur due to the decrease in surface heterogeneity of the adsorbent.

\section{FTIR Analysis of Activated Carbon of Waste tyres Adsorbent}

The FTIR is an important tool to identify characteristic functional groups of the adsorbent, which are capable of adsorbing metal ions. The FTIR spectroscopy provides structural and compositional information on the functional groups presented in the sample. The functional groups present in the activated carbon of waste tyres were investigated by FTIR spectra within the range of $400-4000 \mathrm{~cm}^{-1}$ wave number. Figs. 5, 6 and 7 show the band positions in the FTIR spectra of the activated carbon of waste tyres before and after lead and cadmium adsorption presented in Table 4. The adsorption spectra (Fig. 6) displayed a number of adsorption peaks indicating the complex nature of activated carbon of waste tyres 
and it was composed of various functional groups which are responsible for the binding of lead and cadmium metals. The broad peak at $3000 \mathrm{~cm}^{-1}$ corresponds to the $\mathrm{C}-\mathrm{H}, \mathrm{O}-\mathrm{H}$ and $=\mathrm{C}-\mathrm{H}$ stretching vibrations of alkanes, aromatic and carbonyl acids, thus showing the presence of free hydroxyl groups on the adsorbent surface. The peaks at range from 3900 to 3750 $\mathrm{cm}^{-1}$ are due to the stretching vibration of $\mathrm{O}-\mathrm{H}$. The peak at $2400 \mathrm{~cm}^{-1}$ represents the symmetric C-C stretching of the functional group of alkenes present on the adsorbent surface. The sharp peak at $1680 \mathrm{~cm}^{-1}$ could be due to the $\mathrm{C}=\mathrm{C}, \mathrm{C}=\mathrm{O}$ stretching of alkene, carbonyl and amide stretch. The carboxylic acid groups take part in the adsorption of metal ions from the aqueous solution in addition to the other active sites on the carbon surface. The peak at $1680 \mathrm{~cm}^{-1}$ is attributed to the graphite's characteristic $\mathrm{sp}^{2}$ hybridized $\mathrm{C}=\mathrm{C}$ aromatic skeletal stretching. The peak present at $1575 \mathrm{~cm}^{-1}$ represents the NH (bending) and NO (stretch) stretching vibration of amide and nitro functional groups on the adsorbent surface. While the band at $1350 \mathrm{~cm}^{-1}$ corresponds to the C-F, C-N, and $\mathrm{N}-\mathrm{O}$, was stretching vibrations of alkyl halide, amine and nitro functional groups on the adsorbent surface. The peaks in the region 1050 and $750 \mathrm{~cm}^{-1}$ were associated with adsorption by $\mathrm{C}-\mathrm{Cl}, \mathrm{C}-\mathrm{F}$ and $\mathrm{C}-\mathrm{O}$ groups on the adsorbent surface. It is concluded that the prepared activated carbon material includes oxygen-containing functional groups that provide additional active sites in the adsorption process. The FTIR spectra of activated carbon of waste tyres before and after adsorption of lead (Fig. 5) shows, some of the adsorption peaks are shifted or disappeared and new peaks are formed which was due to the adsorption of lead onto the adsorbent surface. It is evident from this figure that the characteristic adsorption peak of $\mathrm{O}-\mathrm{H}$ stretching vibration was shifted from 3900 and $3075 \mathrm{~cm}^{-1}$ which shows the decrease of free hydroxyl group content due to the interaction between lead and $-\mathrm{OH}$ groups of the adsorbent. The peak $\mathrm{C}-\mathrm{H}$ stretching of alkane at $2860 \mathrm{~cm}^{-1}$ was shifted to $2380 \mathrm{~cm}^{-1}$. The peaks at $2400,1575,750 \mathrm{~cm}^{-1}$ were shifted to $1740,1500,860$ $\mathrm{cm}^{-1}$ due to the presence of carboxyl groups. These changes indicate the interaction between the metal ions and the adsorbent surface. A new peak was formed at $2100 \mathrm{~cm}^{-1}$ and 1740 $\mathrm{cm}^{-1}$ which indicates the possible involvement of alkyne and ester groups in the adsorption process during the adsorption of metal ions onto the surface of the adsorbent surface. It is apparent from Fig. 7 that different functional groups could be responsible for the adsorption of cadmium. After adsorption of cadmium, the asymmetrical stretching vibration at 3900 $\mathrm{cm}^{-1}$ was shifted to $3675 \mathrm{~cm}^{-1}$. This shift in peak indicates the interaction between cadmium and -OH groups of adsorbent due to the presence of alcohols, phenols and carboxylic acid. A new peak at $2830 \mathrm{~cm}^{-1}$ was observed due to the chemical reaction involved in the adsorption process. The peak $\mathrm{C}=\mathrm{O}$ stretch at $1680 \mathrm{~cm}^{-1}$ and $1575 \mathrm{~cm}^{-1}$ were shifted to 1650 $\mathrm{cm}^{-1}$, and $1500 \mathrm{~cm}^{-1}$ due to the presence of carboxyl groups. The peak at $1050 \mathrm{~cm}^{-1}$ was shifted to ${ }^{-1}$ and a new peak was observed at $2830 \mathrm{~cm}^{-1}$, which indicates the involvement of alkyne and ester groups in the adsorption process. The shift in

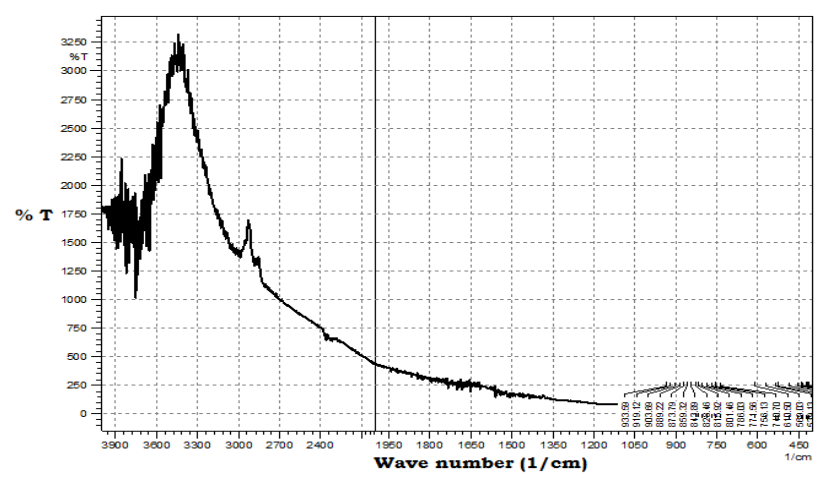

Fig. 5: FTIR spectra of waste tires activated carbon adsorbent before adsorption.

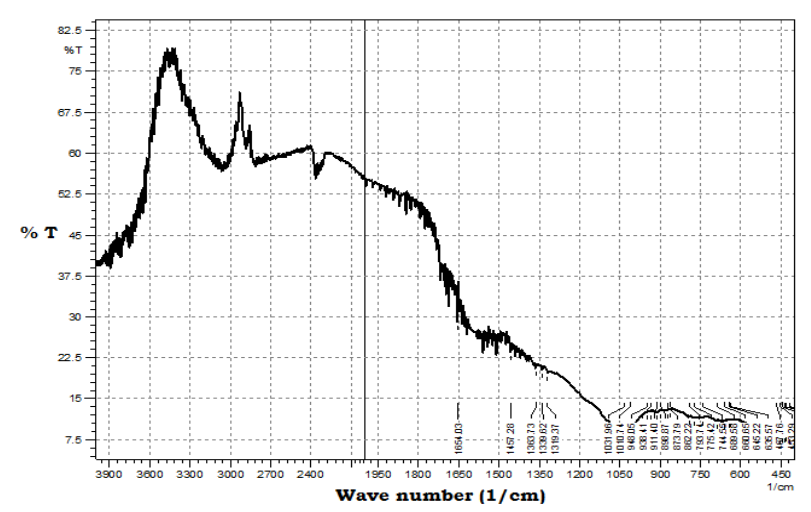

Fig. 6: FTIR spectra of activated carbon of waste tires adsorbent after adsorption of lead.

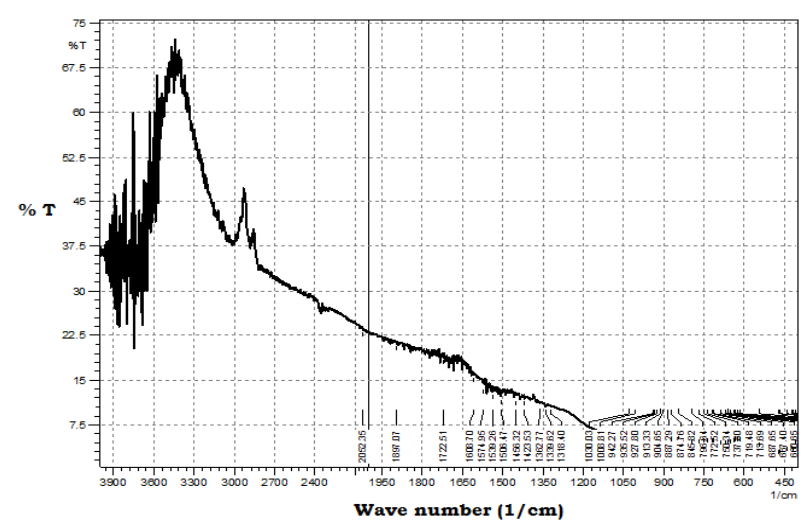

Fig. 7: FTIR spectra of activated carbon of waste tires adsorbent after adsorption of cadmium. 
Table 4: FTIR spectra of activated carbon of waste tires adsorbent.

\begin{tabular}{|c|c|c|c|c|c|c|}
\hline \multicolumn{5}{|c|}{ IR frequency range, $\left(\mathrm{cm}^{-1}\right)$} & \multirow[t]{2}{*}{ Type of vibration } & \multirow[t]{2}{*}{ Functional groups } \\
\hline WTAC & Lead loaded & Diff. & Cadmium loaded & Diff. & & \\
\hline 3900 & 3900 & 0 & 3890 & 10 & $\mathrm{OH}$, Stretch, free & Alcohols \\
\hline 3880 & & & 3825 & 55 & $\mathrm{OH}$, Stretch, free & Alcohols \\
\hline \multirow[t]{2}{*}{3870} & & & 3750 & 120 & $\mathrm{OH}$, Stretch, free & Alcohols \\
\hline & & & 3675 & & $\mathrm{OH}$, Stretch, free & Alcohols \\
\hline 3825 & & & & & $\mathrm{OH}$, Stretch, free & Alcohols \\
\hline 3750 & & & & & $\mathrm{OH}$, Stretch, free & Alcohols \\
\hline 3000 & 3075 & 75 & 3000 & 0 & $\begin{array}{l}\text { C-H, Stretch } \\
\text { O-H, Stretch }(\mathrm{C}=\mathrm{O}) \\
=\mathrm{C}-\mathrm{H}, \text { Stretch }\end{array}$ & $\begin{array}{l}\text { Alkane/Aromatic/Carbonylacid/ } \\
\text { Alkene }\end{array}$ \\
\hline \multirow[t]{2}{*}{2850} & 2860 & 10 & 2850 & 0 & $\begin{array}{l}\text { C-H, Stretch } \\
\text { O-H, Stretch } \\
=\mathrm{C}-\mathrm{H}, \text { Stretch }\end{array}$ & Alkane/ Carbonyl acid/Aldehydes \\
\hline & 2850 & & 2830 & & $\begin{array}{l}\text { C-H, Stretch } \\
\text { O-H, Stretch } \\
=\mathrm{C}-\mathrm{H}, \text { Stretch }\end{array}$ & $\begin{array}{l}\text { Alkane/ Carbonyl acid/ } \\
\text { Aldehydes }\end{array}$ \\
\hline \multirow[t]{3}{*}{2400} & 2380 & -20 & 2390 & 10 & $\mathrm{C}=\mathrm{C}$, stretch & Alkene \\
\hline & 2100 & & & & Stretch & Alkyne \\
\hline & 1740 & & & & $\mathrm{C}=\mathrm{O}$, Stretch & Carbonyl/Aldehyde/Ester \\
\hline 1680 & & & 1650 & 30 & $\begin{array}{l}\mathrm{C}=\mathrm{C}, \text { stretch } \\
\mathrm{C}=\mathrm{O} \text {, stretch } \\
\mathrm{C}=\mathrm{O} \text {, stretch }\end{array}$ & Alkene/Carbonyl/Amide \\
\hline 1575 & 1500 & -75 & 1500 & -75 & $\begin{array}{l}\text { NH, Bending } \\
\text { NO, Stretch }\end{array}$ & Amide/ Nitro \\
\hline 1350 & & & & & $\begin{array}{l}\text { C-F, Stretch } \\
\text { C-N, Stretch } \\
\text { N-O, Stretch }\end{array}$ & Alkyl Halide/Amine/Nitro \\
\hline 1050 & 1050 & & 1040 & 0 & $\begin{array}{l}\mathrm{C}-\mathrm{Cl}, \text { Stretch, } \\
=\mathrm{C}-\mathrm{H}, \text { Bending }\end{array}$ & Alkyl halide/Alkene \\
\hline 750 & 860 & 110 & 750 & 0 & $\begin{array}{l}\text { C-F, Stretch, } \\
\text { C-O, Stretch }\end{array}$ & Alkyl halide/Alcohol \\
\hline
\end{tabular}

peak values could be due to the formation of a chemical bond between the functional groups present on activated carbon of waste tyres and cadmium. FTIR spectrum of raw activated carbon of waste tyres reveals that there was a large number of hydroxyl and carboxyl groups present on the surface of the adsorbent, which possibly reacted with metal ions in an aqueous solution. These groups may largely contribute to the active adsorption sites required for the adsorption of lead and cadmium metal ions. All these observations indicated the possible involvement of functional groups on the surface of the activated carbon of waste tyres in the adsorption process. These results also indicate that chemisorption could also be involved in the adsorption of lead and cadmium metal ions onto the activated carbon of waste tyres. The FTIR is an important tool to identify characteristic functional groups of the adsorbent, which are capable of adsorbing metal ions.

\section{XRD Analysis of Activated Carbon of Waste tyres Adsorbent}

The adsorbent can be crystallographically characterized by means of X-ray diffraction (XRD). Figs. 8, 9 and 10 show the XRD diagram of activated carbon of waste tyres before and after adsorption of lead and cadmium ions. The XRD pattern of raw adsorbent showed a typical spectrum of cellulosic material, with main and secondary peaks at $2 \square$ of $26.42^{\circ}$ and $20.6^{\circ}$ respectively. The height of the peak and the corresponding position angles are shown in Table 5 . The main peak at $26.42^{\circ}$ corresponds to the 002 crystallographic planes and it is taken as indicative of the presence of highly organized crystalline cellulose. The secondary peak at $20.6^{\circ}$ corresponding to the (101) crystal plane and it is a measure of a less organized polysaccharide structure. The planes at 
(002) and (101) indicate the presence of a negative form of cellulose found in the natural source that is cellulose-I polymorphic form. The presence of cellulose indicates the irreversible adsorption of metals through columbic attraction since the negative surface change is acquired by cellulose on contact with water. The cellulose present in the natural materials contains some crystalline oriented zones, which give a certain degree of crystallinity in fibre materials. The crystallinity of the adsorbent strongly depends on the composition of lignin, hemicelluloses and cellulose present in the adsorbent. The crystallinity of the material gives the relative amount of total crystalline material present in cellulose is measured with the help of crystalline index (CI) (Abdulaziz et al. 2013). The CI of the adsorbent was determined using the following equation,

$$
\% C I=\frac{I_{002}-I_{a m}}{I_{002}}
$$

Where, $I_{002}$ and $I_{a m}$ are the intensity of the crystalline peak at $\left(I_{002}, 2 \theta=24.1^{\circ}\right)$ and amorphous peak $\left(I_{a m}, 2 \theta=\right.$ $18.33^{\circ}$ ) of samples respectively. The CI index for raw, lead and cadmium loaded activated carbon of waste tyres were found to be $48.91 \%, 81 \%$ and $54.9 \%$ respectively. These values clearly showed the increase in crystalline material present

Table 5: XRD details of activated carbon of waste tires adsorbent before, and after adsorption of lead and cadmium.

\begin{tabular}{|c|c|c|c|}
\hline \multirow{2}{*}{$\begin{array}{l}\text { Count/ } \\
\mathrm{sec}\end{array}$} & \multicolumn{3}{|c|}{ Activated carbon of waste tires (ACWT) } \\
\hline & $\begin{array}{l}\text { Peak position } \\
(2 \theta) \text { before } \\
\text { adsorption }\end{array}$ & $\begin{array}{l}\text { Peak position } \\
(2 \theta) \text { by lead } \\
\text { loaded }\end{array}$ & $\begin{array}{l}\text { Peak position } \\
(2 \theta) \text { by cadmi- } \\
\text { um loaded }\end{array}$ \\
\hline 76.49 & 6.1541 & 18.7319 & 6.3167 \\
\hline 41.53 & 11.4603 & 19.6817 & 19.7253 \\
\hline 52.31 & 19.5149 & 20.7562 & 20.6987 \\
\hline 239.36 & 20.6081 & 25.1464 & 25.1608 \\
\hline 105.44 & 25.1321 & 26.3881 & 26.4291 \\
\hline 857.57 & 26.4276 & 29.3639 & 29.3962 \\
\hline 102.98 & 29.1980 & 31.0904 & 30.9201 \\
\hline 67.44 & 30.8530 & 36.2937 & 36.3522 \\
\hline 34.22 & 33.1397 & 39.2956 & 39.3081 \\
\hline 81.83 & 36.3922 & 42.2949 & 42.2426 \\
\hline 77.67 & 39.2136 & 45.5652 & 45.6479 \\
\hline 139.26 & 42.1841 & 49.8820 & 47.4495 \\
\hline 38.37 & 43.0645 & 54.7764 & 49.9305 \\
\hline 38.55 & 45.5594 & 59.7418 & 54.6937 \\
\hline 104.88 & 47.3470 & 65.3000 & 59.7431 \\
\hline 159.88 & 49.8569 & 68.0305 & 67.9831 \\
\hline 147.51 & 49.9959 & 73.3603 & 75.5485 \\
\hline 25.42 & 54.7354 & 81.1832 & 79.7290 \\
\hline
\end{tabular}

in the adsorbent after the adsorption of metal ions, which was due to the adsorption of metal ions onto the surface of the adsorbent. These results confirm the SEM micrographs of raw, lead and cadmium-loaded adsorbent. It is evident from the XRD results that significant differences were occurred in the peak intensities for the adsorbent before and after the adsorption of lead and cadmium metals. The peaks obtained from the samples appeared to be largely amorphous. However, some peaks are characteristic of cellulose crystallinity. The results also indicate that the intensity of the peaks was also decreased considerably after the adsorption of lead and cadmium metals. This is due to the destruction of the crystalline structure of activated carbon of waste tyres with the adsorption of metals. The XRD pattern of raw activated carbon of waste tyres showed a characteristic peak at a $2 \theta$ value of $26.42^{\circ}$. After the adsorption, this peak was slightly moved to a lower angle at $26.38^{\circ}$ for lead, which indicates the adsorption of metal ions onto the surface of activated carbon of waste tyres. The secondary peak at $20.6^{\circ}$ for raw adsorbent was slightly moved to a lower angle of $20.75^{\circ}$ after the adsorption of lead and cadmium loaded adsorbent dosage. The peaks at 25.1, 29.1, 36.3, 42.1, 47.3, 49.8 and $49.9^{\circ}$ corresponding to the peaks height (count/sec) at $105.4,102.98,81.83,139.2,104.8,159.88$ and 147.51 were

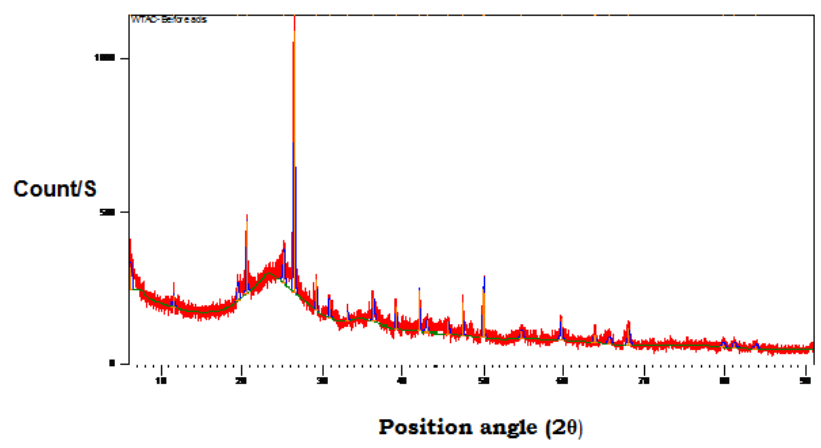

Fig. 8: XRD of activated carbon of waste tires adsorbent before adsorption.

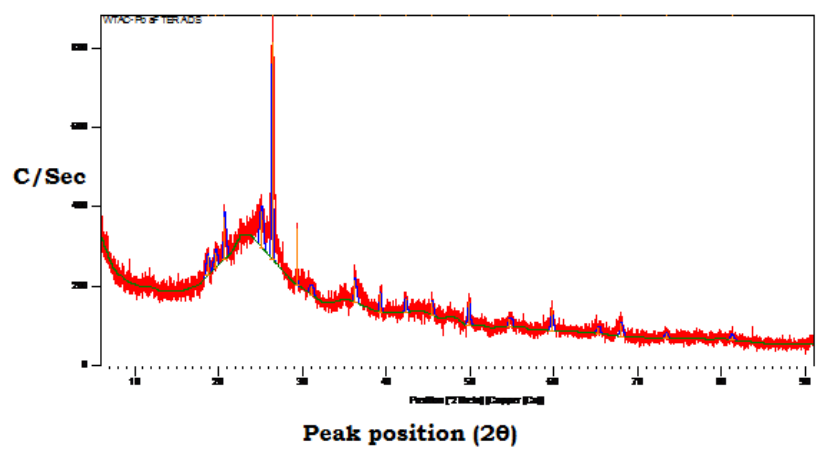

Fig. 9: XRD of activated carbon of waste tires adsorbent after adsorption of lead. 


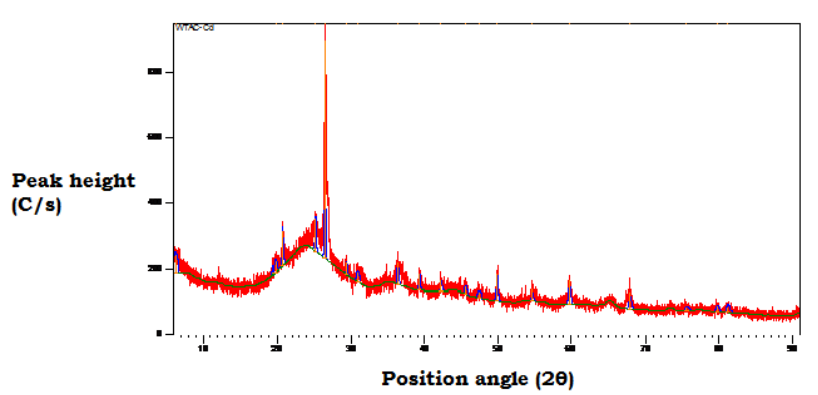

Fig. 10: XRD of activated carbon of waste tires adsorbent after adsorption of cadmium.

slightly changed to $25.1,29.3,36.2,49.8$ and $59.7^{\circ}$ for lead adsorption and 25.16, 36.35, 39.3, 49.9, 59.74 and $67.98^{\circ}$ for cadmium adsorption. New peaks were also observed for lead and cadmium-loaded adsorbent. The shift in peaks, disappearance of peaks and formation of new peaks after adsorption of lead and cadmium samples was due to the chemical reaction involved during the process. Thus, XRD results confirmed that significant interactions were occurring between metal ions and adsorbent surface.

\section{CONCLUSIONS}

Activated carbon was prepared from waste rubber tyres and characterized by means of field emission scanning electron microscopy, energy-dispersive X-ray and Fourier transform infrared spectroscopies.

The functional groups present on the adsorbent the corresponding infrared absorption frequencies are before adsorption at optimum conditions show the broad peak at $3000 \mathrm{~cm}^{-1}$ corresponds to the $\mathrm{C}-\mathrm{H}, \mathrm{O}-\mathrm{H}$ and $=\mathrm{C}-\mathrm{H}$ stretching vibrations of alkanes, aromatic and carbonyl acids, thus showing the presence of free hydroxyl groups on the adsorbent surface.

It is evident that the characteristic adsorption peak of O-H stretching vibration was shifted from 3900 and 3075 $\mathrm{cm}^{-1}$ for lead and the asymmetrical stretching vibration at $3900 \mathrm{~cm}^{-1}$ was shifted to $3675 \mathrm{~cm}^{-1}$ for cadmium. This shift in peak indicates the interaction between metal ions and -OH groups of adsorbent due to the presence of alcohols, phenols and carboxylic acid and which shows the decrease of free hydroxyl group content due to the interaction between lead cadmium with - $\mathrm{OH}$ groups of the adsorbent.

The shift in peak values could be due to the formation of a chemical bond between the functional groups present on activated carbon of waste tyres with metal ions.

FTIR spectrum of raw activated carbon of waste tyres reveals that there was a large number of hydroxyl and carboxyl groups present on the surface of the adsorbent, which possibly reacted with metal ions in an aqueous solution.
These results also indicate that chemisorption could also be involved in the adsorption of lead and cadmium metal ion onto the activated carbon of waste tyres.

It is clear that the adsorbent has a considerable number of heterogeneous layer pores where there is a good possibility of heavy metal being adsorbed. The surface of the adsorbent became smooth after the adsorption of lead and cadmium metals. Smoothening of the surface is due to the adsorption of metal ions onto the pores of the adsorbent. It may also occur due to the decrease in surface heterogeneity of the adsorbent.

It is evident from the XRD results that significant differences were occurred in the peak intensities for the adsorbent before and after the adsorption of lead and cadmium metals. The peaks obtained from the samples appeared to be largely amorphous. However, some peaks are characteristic of cellulose crystallinity. The results also indicate that the intensity of the peaks was also decreased considerably after the adsorption of lead and cadmium metals. This is due to the destruction of the crystalline structure of activated carbon of waste tyres with the adsorption of metals.

\section{REFERENCES}

Abdulaziz, A., Saadi, A., Saleh, T.A. and Vinod Kumar, G. 2013. Spectroscopic and computational evaluation of cadmium adsorption using activated carbon from Rubber tires. Journal of Molecular Liquids, 188: 136-142.

Akunwa, N.K., Muhammad, M.N. and Akunna, J.C. 2014. Treatment of metal-contaminated wastewater: A comparison of low-cost biosorbents, J. Environ. Manage., 146: 517-523.

Amuda, O. S., Giwa, A. A. and Bello, I. A. 2007. Removal of heavy metal from industrial wastewater using modified activated coconut shell carbon. Biochem. Eng. J., 36: 174-181.

Bohli, T., Ouederni, A., Fiol, N. and Villaescusa, I. 2013. Single and binary adsorption of some heavy metal ions from aqueous solutions by activated carbon derived from olive stones. Desalination Water Treat., 70: 1082-1088.

Chowdhury, Z.Z., Zain, S.M., Khan, R.A., Rafique, R.F. and Khalid, K. 2012. Batch and fixed bed adsorption studies of lead (II) cations from aqueous solutions onto granular activated carbon derived from Mangostana garcinia shell. Bioresources, 7: 2895-2915.

Debasree, P., Umesh, M. and Swarup, B. 2014. A comprehensive review on Cd (II) removal from aqueous solution. Journal of Water Process Engineering, 2:105-128.

Foo, K.Y. and Hameed, B.H. 2010. Insights into the modeling of adsorption isotherm systems. Rev. Chem. Eng., 156: 2-10.

Fu, F. and Wang, Q. 2011. Removal of heavy metal ions from wastewaters: a review. J. Environ. Manage., 92: 407-418.

Girods, P., Dufour, A., Fierro, V., Regime, Y., Rogaumea, C. and Zoulaliana, A. 2011. Activated carbons prepared from wood particleboard wastes: Characterization and phenol adsorption capacities. J. Hazard. Mater., 188: 917-921.

Gupta, V.K., Bina, G., Arshi, R., Shilpi, A. and Arunima, N. 2011a. A comparative investigation on adsorption performances of mesoporous activated carbon prepared from waste rubber tire and activated carbon for a hazardous azo dye-Acid Blue 113. J. Hazard. Mater., 186: 891-901. 
Gupta, V.K., Bina, G., Arshi, R., Shilpi, A. and Arunima, N. 2011b. Pesticides removal from wastewater by activated carbon prepared from waste rubber tire. Wat. Res., 45: 4047-4055.

Juan, D.M., Neus, P., Ramon, M., Tomas, G., Marıa Victoria, N., and Ana, M.M. 2013. Waste tyre pyrolysis-a review. Renewable and Sustainable Energy Reviews, 23: 179-213.

Kobya, M., Demirbas, E., Senturk, E. and Ince, M. 2005. Adsorption of heavy metal ions from aqueous solutions by activated carbon prepared from apricot stone. Bioresour. Technol., 96: 1518-1521.

Krishnan, K. A. and Anirudhan, T.S. 2002. Uptake of heavy metals in batch systems by sulfurized steam activated carbon prepared from sugarcane bagasse pith. Ind. Eng. Chem. Res., 41: 5085-5093.

$\mathrm{Ku}$, Y. and Peters, R.W. 1987. Innovative uses from carbon adsorption of heavy metals from plating wastewaters: Activated carbon polishing treatment. Environ. Prog., 6(2): 119-124.

Momcilovic, M., Purenovic, M., Bojic, A. and Zarubica, A., Randelovid, M. 2011. Removal of lead (II) ions from aqueous solutions by adsorption onto pinecone activated carbon. Desalination Water Treat., 276: 53-59.

Mona, K., Ahmad, K. and Hanafy, H. 2014. Heavy metals removal using activated carbon, silica and silica activated carbon composite. Energy Procedia, 50: 113-120.

Nadeem, M., Mahmood, A., Shahid, S. A., Shah, S. S., Khalid, A. M. and McKay, G. 2006. Sorption of lead from aqueous solution by chemically modified carbon adsorbents. J. Hazard. Mater., 138: 604-613.

Nagajyoti, P.C., Lee, K.D. and Sreekanth, T.V.M. 2010. Heavy metals, occurrence and toxicity for plants: a review. Environ. Chem. Lett., 8(3): 199-216.

Umar, I.G., Emmanuel, O. and Abdul, H.A. 2015. Adsorption of aqueous $\mathrm{Cd}$ (II) and $\mathrm{Pb}$ (II) on activated carbon nanopores prepared by chemical activation of doum palm shell. Springer Plus, 4: 458.

Venkatesan, G. and Senthilnathan, U. 2013. Adsorption batch studies on the removal of cadmium using wood of derris indica based activated carbon. Research Journal of Chemistry and Environment, 17(5). 